\title{
Circadian variation of left ventricular diastolic function in healthy people
}

\author{
Seppo Voutilainen, Markku Kupari, Mikko Hippelainen, Kari Karppinen, Markku Ventila
}

\begin{abstract}
Aim-To assess whether left ventricular function shows circadian variation in healthy people.
\end{abstract}

Subjects and methods-10 healthy men (7) and women (3) aged 35-50 underwent $M$ mode echocardiography of the left ventricle and Doppler velocimetry of transmitral flow at $4 \mathrm{~h}$ intervals over $24 \mathrm{~h}$. The participants were in hospital over the study period and their diet, meal times, and sleeping hours were standardised as far as possible.

Measurements-Heart rate, blood pressure, left ventricular and atrial diameters, fractional shortening, peak early and late transmitral velocities, time from the second heart sound to the early diastolic velocity peak (relaxation time), isovolumic relaxation period, acceleration and deceleration of the early transmitral flow, atrial filling fraction.

Results-A circadian rhythm was observed in heart rate and blood pressure, but neither the left ventricular diameters and systolic function nor the left atrial size showed statistically significant diurnal trends. The relaxation time (mean (SD)) measured 144 (16) $\mathrm{ms}$ at 2 $\mathrm{pm}, 144(21) \mathrm{ms}$ at $6 \mathrm{pm}, 149$ (22) $\mathrm{ms}$ at $10 \mathrm{pm}, 168(23) \mathrm{ms}$ at $2 \mathrm{am}, 174(28) \mathrm{ms}$ at $6 \mathrm{am}$, and $151(21) \mathrm{ms}$ at $10 \mathrm{am}(\mathrm{P}=$ 0.009). Diurnal rhythms were seen also in the isovolumic relaxation period $(P=$ $0 \cdot 003)$ and in the acceleration of the early diastolic transmitral flow $(P=0.037)$; the lowest and highest values of flow acceleration were observed during the nocturnal and daytime hours, respectively.

Conclusions-The Doppler indices of left ventricular filling in healthy people show diurnal changes suggestive of a circadian rhythm in the rate of left ventricular relaxation. The most likely underlying mechanism is the day-night cycle in sympathoadrenal activity.

(Heart 1996;75:35-39)

Keywords: circadian rhythm; left ventricular function; Doppler velocimetry

The normal fluctuation of human circulatory function includes a circadian rhythm thought to reflect the rest-activity cycle and the variation of the sympathetic and vagal nervous activities. The rhythm is best seen in heart rate and blood pressure ${ }^{1-3}$ but has recently also been identified by impedance cardiography in cardiac output and peripheral vascular resistance. ${ }^{1}$ Apart from some contradictory observations on diurnal variation in left ventricular ejection time, ${ }^{14}$ there are no data to show whether left ventricular function varies with the time of day in normal man. Cardiac ultrasound combined with Doppler velocimetry of transmitral flow affords a means to characterise left ventricular systolic and diastolic performance fully atraumatically, repeatedly, and without disturbing the prevailing function of the heart and circulation. In this study, we have used these techniques to assess the diurnal variation of left ventricular function in a group of healthy middle aged subjects. We were particularly interested in the time trends of the Doppler transmitral velocity indices because recent studies have shown that diastolic function may be more sensitive than systolic function to both physiological and pathophysiological influences on the heart. ${ }^{56}$

\section{Methods}

SUBJECTS

We examined 10 healthy voluntary subjects ( 7 men, 3 women) aged 35 to 50 years (mean, 42 years). Their body mass index (mean (SD)) was $24.0(4 \cdot 0) \mathrm{kg} / \mathrm{m}^{2}$. None had a history, symptoms, or signs of cardiovascular or systemic diseases. All had normal findings at clinical examination and in a comprehensive cardiac ultrasound study. The 12-lead electrocardiogram was also normal in each subject. All except one man were non-smokers, and none had a history of excessive habitual alcohol use. Five subjects were physically active but none was or had been engaged in competitive sports.

\section{DESIGN OF THE STUDY}

To standardise and synchronise their daily routines, the subjects were admitted to hospital for the period of the study. They entered the ward at noon on day 1 , and underwent $M$ mode and Doppler echocardiographic examinations and measurement of brachial artery cuff blood pressure first at $2 \mathrm{pm}$ and thereafter at $4 \mathrm{~h}$ intervals regularly up to $10 \mathrm{am}$ in the morning of day 2 . In the intervening periods, the subjects were free to move in the hospital except that each echocardiographic study was preceded by a minimum of $15 \mathrm{~min}$ of complete supine rest. The subjects went to bed at $10 \mathrm{pm}$ on day 1 and were wakened at 6 am the next morning. The morning examination was 
made directly after awakening before any morning activities. The subjects also woke up temporarily at the time of the examination performed in the middle of the sleeping period ( $2 \mathrm{am})$. All participants were on a standard hospital diet during the study; the meals were given at $4 \mathrm{pm}$ and $7 \mathrm{pm}$ on day 1 and at 7 am in the morning of day 2 . The study protocol was approved by the local ethics committee.

\section{ECHOCARDIOGRAPHY}

The ultrasound examination consisted of $M$ mode recordings to assess left atrial size and left ventricular systolic function and a Doppler study of transmitral flow to assess left ventricular diastolic function. The techniques have been described in detail in our earlier reports. ${ }^{78}$ All examinations were performed with an instrument combining a pulsed Doppler velocimeter with a sector scanner and a strip chart recorder (Hewlett Packard 77020A). A 2.5/3.5 MHz transducer was used. An external phonocardiogram and an electrocardiogram were taken simultaneously with the $M$ mode and Doppler tracings. A minimum of five cardiac cycles were recorded during quiet expiration; the chart speed was $50 \mathrm{~mm} / \mathrm{s}$. The subjects lay in a left lateral recumbent position throughout the study.

The $M$ mode recordings of the left ventricle and left atrium were obtained through a parasternal cross sectional long axis view of the heart. The recordings were analysed later to determine the left ventricular end diastolic and end systolic diameters and the systolic diameter of the left atrium. ${ }^{7}$ Fractional shortening was calculated as (left ventricular end diastolic diameter minus left ventricular end systolic diameter)/left ventricular end diastolic diameter. The ratio of systolic blood pressure to left ventricular end systolic dimension was calculated as another index of systolic function. ${ }^{9}$ All data were averaged over three to five cycles.

The Doppler recordings of transmitral flow were taken through an apical four or two chamber view as recently described. ${ }^{7}$ In short, the ultrasound beam was directed as parallel as possible to the transmitral flow, and the sampling gate was positioned at the level of the mitral anulus. With minor additional adjustments of the transducer, sharply defined velocity envelopes could be recorded in all subjects. The recordings were analysed later by tracing the modal velocities on a tablet digitiser, and the following Doppler indices were determined $^{710}$ : peak early diastolic velocity; peak late diastolic (atrial) velocity; early-to-atrial peak velocity ratio; total diastolic velocity-time integral; time from the onset of the aortic component of the second heart sound to the point of peak early velocity, that is, the relaxation time; acceleration of the early flow; deceleration of the early flow; the ratio of the atrial to the total velocity-time integral, that is, the atrial filling fraction; and the ratio of the peak early velocity to the total velocity-time integral, that is, the peak filling rate normalised to the mitral stroke volume. ${ }^{11}$ The two components of the relaxation time, that is the isovolumic relaxation period and the acceleration time, were also determined separately, on a later occasion. The former was measured as the interval from the aortic second heart sound to the onset of diastolic transmitral flow and the latter as the time from the onset of diastolic flow to its early peak. Heart rate was determined from $Q-Q$ intervals in the electrocardiogram. Five cardiac cycles were averaged for each measurement.

The $M$ mode and Doppler echocardiographic measurements taken in this study have been validated for reproducibility in our laboratory. ${ }^{7}{ }^{10} 12$ All recordings were measured without knowing the time of examination.

\section{STATISTICAL ANALYSIS}

Repeated measurements analysis of variance was used to test whether the cardiovascular measurements showed consistent changes with the time of day. In testing the null hypothesis of no variation, we used the multivariate repeated measurements $\mathrm{F}$ statistic provided by the SPSS/PC + statistical package (version 4.0.1) because the data did not conform with all requirements of the univariate analysis technique. It should be noted that the use of multivariate $F$ statistic minimises the risk of chance findings but reduces the power of the analyses. $P$ values $<0.05$ were considered statistically significant. The results are given as mean (SD).

\section{Results}

Table 1 summarises the data on heart rate, blood pressure, and $M$ mode echocardiographic measurements at $4 \mathrm{~h}$ intervals throughout the study period. As expected, heart rate and blood pressure varied with the

Table 1 Haemodynamic and $M$ mode echocardiographic measurements in healthy subjects at $4 h$ intervals over $24 h$. Values are means (SD), $n=10$

\begin{tabular}{|c|c|c|c|c|c|c|c|}
\hline \multirow[b]{2}{*}{ Variable } & \multicolumn{6}{|c|}{ Hour of the day } & \multirow[b]{2}{*}{$P^{*}$} \\
\hline & $02 \mathrm{pm}$ & $06 \mathrm{pm}$ & $10 \mathrm{pm}$ & $02 \mathrm{am}$ & $06 \mathrm{am}$ & $10 \mathrm{am}$ & \\
\hline $\begin{array}{l}\text { Heart rate (beats/min) } \\
\text { Systolic blood pressure (mm Hg) } \\
\text { Diastolic blood pressure }(\mathrm{mm} \mathrm{Hg}) \\
\text { Left ventricular }\end{array}$ & $\begin{array}{r}64(10) \\
127(8) \\
77(6)\end{array}$ & $\begin{array}{r}65(11) \\
123(14) \\
73(6)\end{array}$ & $\begin{array}{r}62(10) \\
118(12) \\
76(10)\end{array}$ & $\begin{array}{r}58(10) \\
116(13) \\
71(9)\end{array}$ & $\begin{array}{c}55(8) \\
113(10) \\
72(9)\end{array}$ & $\begin{array}{r}61(10) \\
120(16) \\
76(7)\end{array}$ & $\begin{array}{l}0.055 \\
0.016 \\
0.151\end{array}$ \\
\hline $\begin{array}{l}\text { end diastolic diameter }(\mathrm{mm}) \\
\text { end systolic diameter }(\mathrm{mm}) \\
\text { fractional shortening }(\%) \\
\text { end systolic pressure/diameter ratio } \\
(\mathrm{mm} \mathrm{Hg}) \dagger\end{array}$ & $\begin{array}{l}49(4) \\
31(4) \\
37(4) \\
4 \cdot 2(0 \cdot 7)\end{array}$ & $\begin{array}{l}49(5) \\
32(4) \\
36(4) \\
3.9(0 \cdot 5)\end{array}$ & $\begin{array}{l}49(5) \\
29(5) \\
40(6) \\
4 \cdot 0(0 \cdot 6)\end{array}$ & $\begin{array}{l}49(6) \\
32(5) \\
35(4) \\
3 \cdot 7(0 \cdot 7)\end{array}$ & $\begin{array}{l}49(5) \\
31(5) \\
36(4) \\
3 \cdot 7(0 \cdot 7)\end{array}$ & $\begin{array}{l}49(6) \\
31(5) \\
37(4) \\
4 \cdot 0(0 \cdot 8)\end{array}$ & $\begin{array}{l}0 \cdot 531 \\
0 \cdot 142 \\
0 \cdot 085 \\
0 \cdot 168\end{array}$ \\
\hline Left atrial diameter $(\mathrm{mm})$ & $32(5)$ & $32(5)$ & $32(4)$ & $32(4)$ & $31(2)$ & $32(5)$ & $0 \cdot 857$ \\
\hline
\end{tabular}

†Cuff systolic blood pressure/left ventricular end systolic diameter

$\star \mathrm{P}$ values from repeated measurements analysis of variance. 
Table 2 Doppler indices of diastolic transmitral flow in healthy subjects at $4 h$ intervals over $24 h$. Values are means (SD), $n=10$

\begin{tabular}{|c|c|c|c|c|c|c|c|}
\hline \multirow[b]{2}{*}{ Variable } & \multicolumn{6}{|l|}{ Hour of the day } & \multirow[b]{2}{*}{$P^{*}$} \\
\hline & $02 \mathrm{pm}$ & $06 \mathrm{pm}$ & $10 \mathrm{pm}$ & $02 \mathrm{am}$ & $06 \mathrm{am}$ & $10 \mathrm{am}$ & \\
\hline $\begin{array}{l}\text { Peak early velocity }(\mathrm{cm} / \mathrm{s}) \\
\text { Peak atrial velocity }(\mathrm{cm} / \mathrm{s}) \\
\text { Early-to-atrial peak velocity ratio } \\
\text { Relaxation time }(\mathrm{ms}) \\
\text { Acceleration of early velocity }\left(\mathrm{cm} / \mathrm{s}^{2}\right) \\
\text { Deceleration of early velocity }\left(\mathrm{cm} / \mathrm{s}^{2}\right) \\
\text { Total flow velocity integral }(\mathrm{cm}) \\
\text { Peak filling rate }\left(\mathrm{s}^{-1}\right) \\
\text { Atrial filling fraction }(\%)\end{array}$ & $\begin{array}{l}64(6) \\
43(8) \\
1 \cdot 6(0 \cdot 4) \\
144(16) \\
812(170) \\
451(89) \\
12 \cdot 8(2 \cdot 2) \\
5 \cdot 1(0 \cdot 7) \\
0 \cdot 27(0 \cdot 07)\end{array}$ & $\begin{array}{l}62(8) \\
39(7) \\
1 \cdot 7(0 \cdot 5) \\
144(21) \\
814(228) \\
428(79) \\
12 \cdot 2(1 \cdot 8) \\
5 \cdot 1(0 \cdot 6) \\
0 \cdot 27(0 \cdot 09)\end{array}$ & $\begin{array}{l}65(10) \\
41(6) \\
1 \cdot 6(0 \cdot 4) \\
149(22) \\
817(218) \\
423(100) \\
13 \cdot 2(2 \cdot 5) \\
5 \cdot 0(0 \cdot 8) \\
0 \cdot 24(0 \cdot 07)\end{array}$ & $\begin{array}{l}59(10) \\
37(6) \\
1 \cdot 6(0 \cdot 4) \\
168(23) \\
714(194) \\
391(122) \\
12 \cdot 8(2 \cdot 5) \\
4 \cdot 7(0 \cdot 7) \\
0 \cdot 23(0 \cdot 07)\end{array}$ & $\begin{array}{l}61(9) \\
37(5) \\
1 \cdot 7(0 \cdot 4) \\
174(28) \\
700(189) \\
416(110) \\
13 \cdot 5(2 \cdot 3) \\
4 \cdot 6(0 \cdot 5) \\
0 \cdot 25(0 \cdot 08)\end{array}$ & $\begin{array}{l}61(11) \\
41(8) \\
1 \cdot 6(0 \cdot 6) \\
151(21) \\
822(264) \\
398(86) \\
12 \cdot 7(2 \cdot 3) \\
4 \cdot 8(0 \cdot 5) \\
0 \cdot 28(0 \cdot 09)\end{array}$ & $\begin{array}{l}0.322 \\
0 \cdot 172 \\
0 \cdot 350 \\
0 \cdot 009 \\
0 \cdot 037 \\
0.691 \\
0.614 \\
0 \cdot 100 \\
0.668\end{array}$ \\
\hline
\end{tabular}

${ }^{\star} \mathbf{P}$ values from repeated measurements analysis of variance.

time of day, both being lowest at night and highest in the afternoon and early evening. By contrast, neither the left ventricular dimensions or systolic function nor the left atrial diameter showed statistically significant diurnal trends.

The Doppler indices of left ventricular diastolic function are summarised in table 2 . The relaxation time and the acceleration of the early diastolic flow manifested statistically sig-

The individual diurnal trends of heart rate $(A)$, systolic blood pressure (B), relaxation time $(C)$, and acceleration of early diastolic transmitral flow (D) in 10 healthy persons studied by cardiac

ultrasound at $4 h$ intervals in a standardised hospital setting. The $P$ values in the figures are from repeated measurements analysis of variance.
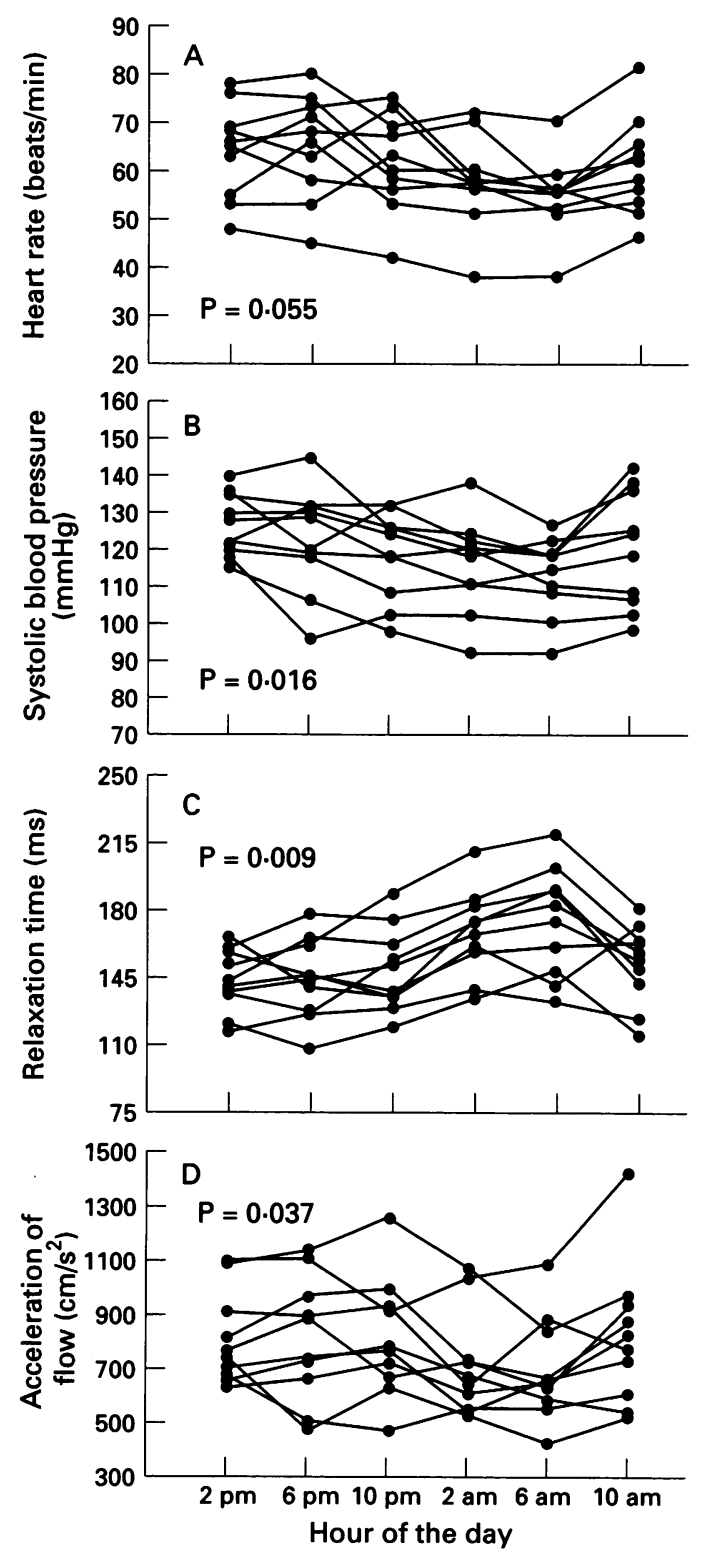

nificant diurnal changes in the study group. The relaxation time was clearly longer, and the flow acceleration lower, at night and at awakening in the morning than during the active hours of the day. Of the two components of the relaxation time, the duration of the isovolumic period showed a prominent diurnal rhythm measuring $66(15) \mathrm{ms}$ at $2 \mathrm{pm}, 64$ (10) $\mathrm{ms}$ at $6 \mathrm{pm}, 69(15) \mathrm{ms}$ at $10 \mathrm{pm}, 92$ (17) $\mathrm{ms}$ at $2 \mathrm{am}, 92$ (19) $\mathrm{ms}$ at $6 \mathrm{am}$, and 71 (16) $\mathrm{ms}$ at $10 \mathrm{am}(P=0.003)$. The other component, the acceleration time, varied less with the time of day, from a trough of 71 (9) $\mathrm{ms}$ at $2 \mathrm{pm}$ to a peak of $83(16) \mathrm{ms}$ at 6 am (P $=0.326)$. Although the transmitral velocity peaks and the peak filling rate were higher during the daytime hours than at night, the time trends in these variables were not statistically significant (table 2). The individual diurnal changes in heart rate, systolic blood pressure, relaxation time, and flow acceleration are shown in the figure.

\section{Discussion}

Our study reproduced the well known circadian variation of heart rate and blood pressure and showed, as a novel finding, that certain characteristics of left ventricular diastolic function also have diurnal changes in normal man. The diameters and systolic function of the left ventricle were clearly less dependent on the time of day.

Left ventricular filling is determined by the rate of active early diastolic ventricular relaxation and by passive ventricular compliance that governs the late diastolic inflow and includes the effect of atrial contraction..$^{51314}$ Relaxation reflects the biochemical inactivation of the crossbridges between the actin and myosin filaments and is, in addition, related to the loading conditions of the left ventricle and to the synchrony of its function. ${ }^{13}$ Compliance in turn is determined by the passive elasticity of the heart muscle, the shape and wall thickness of the left ventricle, the degree of pericardial compression, and the interaction of the ventricles. ${ }^{5614}$ The rate of relaxation is very sensitive to changes in neurohumoral activity and myocardial metabolism, ${ }^{6}{ }^{13}$ while the passive diastolic pressure-volume curve, which best describes ventricular compliance, can be assumed to remain stable over short periods of time in normal conditions. Doppler velocimetry of transmitral flow provides a convenient and 
reproducible means to assess left ventricular filling non-invasively. ${ }^{61516}$ The early phase of filling can be characterised by measuring the duration of isovolumic relaxation, the acceleration of flow, and the early diastolic peak velocity and peak filling rate. The left ventricular relaxation rate is the key determinant of these indices together with left atrial pressure ${ }^{6}{ }^{14}$; the isovolumic relaxation time depends additionally on left ventricular systolic and aortic diastolic pressure. ${ }^{17}$ Given constant loading conditions, a reduction of the relaxation rate prolongs the isovolumic relaxation time and decreases the acceleration and the peak of the early diastolic velocity. ${ }^{14} \mathrm{~A}$ reduction of left atrial pressure causes similar changes given a constant rate of relaxation. ${ }^{14}$

In our subjects, the left ventricular relaxation time, and its isovolumic period in particular, was clearly longer at night and directly after awakening in the morning than during the active hours of the day. The diurnal cycle in the acceleration of the early diastolic flow mirrored the variation of the relaxation time: acceleration was lower when the relaxation time was long and grew higher as the relaxation time became shorter. Supportive, though statistically non-significant, trends were seen also in the peak early diastolic velocity and in the peak filling rate (see table 2). Most probably, the diurnal variation of early diastolic left ventricular filling reflects variation in the rate of ventricular relaxation. The small changes in blood pressure cannot explain these findings, ${ }^{18}$ and previous work also shows that the relaxation time is relatively insensitive to changes in heart rate. ${ }^{819}$ In our own earlier study, atropine-induced increases of 10 to 20 beats/min in heart rate had no effect on the relaxation time, ${ }^{8}$ and in the study by Stewart et $a l^{19}$ each 10 beat $/ \mathrm{min}$ alteration of heart rate produced less than a $5 \%$ change in the duration of isovolumic relaxation. In the present work, by contrast, a diurnal difference of 10 beats $/ \mathrm{min}$ in the mean heart rate was associated with a $20 \%$ difference in the duration of relaxation (see tables 1 and 2), suggesting that other factors besides the heart rate change were also influential. A nocturnal reduction of left atrial pressure is an alternative explanation for the circadian rhythm of relaxation time and flow acceleration observed in this study. However, we have found no data indicating either directly or indirectly-that left atrial pressure would consistently fall at night in the normal human. Instead it has been shown that the central blood volume increases at night in healthy persons, ${ }^{1}$ which suggests that the cardiac filling pressures might be increased rather than lowered nocturnally unless the compliance of the pulmonary vasculature undergoes truly a major increase. Ambulatory pulmonary artery pressure monitoring has in fact shown an increase of diastolic pulmonary artery pressure (an indirect index of left atrial pressure) at night both in normal subjects and in cardiac patients. ${ }^{20}$ Importantly, the peak values of pulmonary artery diastolic pressure were observed several hours after lying down, at 2 to $3 \mathrm{am}$, suggesting that the immediate postural increase of venous return and intrathoracic blood volume was not the sole explanation. ${ }^{20}$ Understandably we could not directly monitor left atrial pressure in our healthy volunteers, but the lack of any changes in the left ventricular end diastolic diameter or left atrial diameter (see table 1) suggests that the left heart filling pressures remained relatively stable throughout the day. For these reasons, we consider a nocturnal fall in the rate of left ventricular relaxation a much more likely explanation of our findings than a fall in left atrial pressure.

The inactivation of the myocardial actomyosin complexes and the rate of ventricular relaxation are intimately related to $\beta$ adrenergic stimulation and the prevailing sympathoadrenal activity. ${ }^{6}$ The circadian variation of left ventricular diastolic function could therefore reflect the well known cyclic variation in sympathoadrenal activity, ${ }^{21}{ }^{22}$ with its nocturnal withdrawal and daytime increase resulting in reduced and augmented rate of ventricular relaxation, respectively. We did not measure the sympathoadrenal activity in our subjects, however, and therefore this explanation remains tentative. Yet it is likely that the same basic mechanisms underlie the diurnal changes in heart rate, blood pressure, and left ventricular function. We also emphasise that, although systolic function showed no statistically significant changes, diurnal variation in contractility cannot be excluded because the nocturnal fall of systolic blood pressure was accompanied by a trend towards lower rather than higher left ventricular ejection performance, notwithstanding maintained preload (end diastolic diameter).

Our study was limited to healthy persons, and the data are therefore applicable only to normal left ventricular physiology. How cardiac diseases modify the circadian variation of left ventricular function and whether the possible diurnal changes have any pathophysiological importance needs to be addressed in future work. In theory, delayed rate of left ventricular relaxation could compromise coronary artery perfusion at night, the more so as aortic diastolic pressure is at the same time reduced. Nocturnal ischaemia is not uncommon in coronary artery disease, but otherwise many acute cardiovascular events tend to occur in the morning. ${ }^{2}$ The small size of our study population is another limitation of our work. Although a larger study group had increased the statistical power of our analyses there is litthe to suggest that the key findings would have been different. A methodological point worthy of comment is the way the left ventricular relaxation time was determined. We adhered here to our earlier practice ${ }^{7810}$ and measured the relaxation time from the second heart sound to the point of the peak early diastolic velocity. In addition to the phase of isovolumic relaxation, this period encompasses the flow acceleration time, which is identical to the duration of the first positive atrioventricular pressure gradient. ${ }^{23}$ Our measurement is therefore likely to cover the relaxation phase more completely than the isovolumic relaxation time 
does. Nonetheless, in this study the diurnal changes in the relaxation time were mainly related to changes in the duration of the isovolumic period since the acceleration time did not show a statistically significant circadian rhythm.

In summary, the fluctuation of left ventricular diastolic function in normal man includes a circadian cycle suggestive of a nocturnal decrease and a daytime increase in the rate of left ventricular relaxation. This variation is compatible with and is tentatively attributed to diurnal changes in sympathoadrenal activity.

This work was supported by grants from Heart Research This work was supported by grants from Heart Research
Foundation (Sydäntutkimussäätiö), Helsinki, Finland, and Foundation (Sydäntutkimussätió), Helsin

1 Cugini P, Di Palma L, Di Simone P, et al. Circadian rhythm of cardiac output, peripheral vascular resistance, and related variables by a beat-to-beat monitoring. Chronobiol Int 1993;10:73-8.

2 Muller JE, Tofler GH, Stone PH. Circadian variation and triggers of onset of acute cardiovascular disease. triggers of onset of acute.

3 Pickering TG, Harshfield GA, Kleinert HD, Blank S, Laragh $\mathrm{JH}$. Blood pressure during normal daily activities sleep and exercise. Comparison of values in normal an hypertensive subjects. $\mathscr{f} A M A 1982 ; 247: 992-6$.

4 Aronow WS, Harding PR, DeQuattro V, Isbell B. Diurna variation of plasma catecholamines and systolic tim intervals. Chest 1973;63:722-6.

5 Kupari $M$. Diastolic heart function and failure. 7 Interm Med 1991;229:479-81.

6 Nishimura RA. Assessment of diastolic function of the heart: background and current applications of Dopple echocardiography. Part I. Physiologic and pathophysiologic features. Mayo Clin Proc 1989;64:71-81.

7 Voutilainen S, Kupari M, Hippeläinen M, Karppinen K, Ventilä M, Heikkilä J. Factors influencing Doppler indexes of left ventricular filling in healthy persons. $A m \mathcal{F}$ Cardiol 1991;68:653-9.

8 Voutilainen S, Kupari $M$, Hippeläinen M, Karppinen K, Ventilä $M$. Age-dependent influence of heart rate on Ventilä $M$. Age-dependent influence of heart rate on Doppler indexes

9 Dehmer GJ, Lewis SE, Hillis LD, Corbett J, Parkey RW, Willerson JT. Exercise-induced alterations in left ventricular volumes and the pressure-volume relationship: sensitive indicator of left ventricular dysfunction in patients with coronary artery disease. Circulation 1981; 63:1008-18

10 Kupari $M$, Koskinen $P$, Hynynen $M$, Salmenperä $M$, Ventilä $M$. Acute effects of ethanol on left ventricular diastolic function by Doppler echocardiography. Br Hear f 1990;64:129-32.

11 Bowman LK, Lee FE, Jaffe CC, Mattera J, Wackers FJ, Zarret BL. Peak filling rate normalized to mitral stroke volume: a new Doppler echocardiographic filling index validated by radionuclide angiographic technique $7 \mathrm{Am}$ Coll Cardiol 1989;12:937-43.

12 Kupari M. Reproducibility of the M-mode echocardiographic assessment of left ventricular function: effect of the temporal range of measurements. Eur Heart $f$ 1984;5:412-8.

13 Brutsaert DL, Rademakers FE, Sys SU, Gillebert TC Housmans PR. Analysis of relaxation in the evaluation of ventricular function of the heart. Prog Cardiovasc Dis ventricular function

14 Thomas JD, Weyman AE. Echocardiographic Doppler evaluation of left ventricular diastolic function. Physics and physiology. Circulation 1991;84:977-89.

15 Appleton CP, Carucci MJ, Henry CP, Olajos M. Influence of incremental changes of heart rate on mitral flow velocity: assessment in lightly sedated, conscious dogs. $\mathcal{F} \mathrm{Am}$ Coll Cardiol 1991;17:227-36.

16 Spirito P, Maron BJ, Bonow RO. Noninvasive assessment of left ventricular diastolic function: comparative analysis of Doppler echocardiographic and radionuclide angioo popler echocardiographic and radionuclide angio

17 Thomas JD, Flachskampf FA, Cheng C, et al. Isovolumic relaxation time varies predictably with its time constant relaxation time varies predictably with its time constant and aortic and left atrial pressures: implications for the noninvasive evaluation of

18 Takenaka K, Shiota T, Sakamoto T, et al. Effect of acute systemic blood pressure elevation on left ventricular filling with and without mitral regurgitation. $\mathrm{Am} \mathcal{F}$ Cardio 1989;63:623-5.

19 Stewart RAH, Joshi J, Alexander N, Nihoyannopoulos P. Adjustment for the influence of age and heart rate on Doppler measurements of left ventricular filling. $\mathrm{Br} \mathrm{Heart}$ f 1992;68:608-12.

20 Levy RD, Cunningham D, Shapiro LM, Wright C, Mockus D, Fox KM. Diurnal variation in left ventricular function: a study of patients with myocardial ischemia syndrome $\mathrm{X}$, and of normal controls. $\mathrm{Br}$ Heart $f$ 1987;57:148-53.

21 Furlan R, Guzzetti S, Crivellaro W, et al. Continuous 24 hour assessment of the neural regulation of systemic arterial pressure and RR variabilities in ambulant subjects. Circulation 1990;81:537-47.

22 Linsell CR, Lightman SL, Mullen PE, Brown MJ, Causon RC. Circadian rhythms of epinephrine and norepinephRC. Circadian rhythms of epinephrine and norepineph-

23 Courtois M, Kovacs SJ, Ludbrook PA. Transmitral pressure-flow velocity relation: importance of regional pressure gradients in the left ventricle during diastole. Circulation 1988;78:661-71. 